\title{
O AGIR EM PSICOSSOCIOLOGIA DO TRABALHO ${ }^{1}$
}

ACTING IN PSYCHOSOCIOLOGY OF WORK

EL AGIR EN PSICOSOCIOLOGIA DEL TRABAJO

Dominique Lhuilier*

Em homenagem a Jacqueline Barus-Michel

\begin{abstract}
RESUMO
Neste artigo, buscaremos esclarecer os sentidos dados aos termos agir, ação, atividade, ato, práxis, conceitos próximos, mas não sinônimos. Para isso, vamos propor uma discussão através da conceitualização da atividade, em psicossociologia do trabalho, centrando-nos em duas questões essenciais: a que serve a atividade? Quais as relações entre atividade e trabalho? A atividade está no fundamento da construção do sujeito e das unidades sociais. Com efeito, as atividades humanas são, a um só tempo, produção de si e do mundo. Além disso, salientamos aqui a unidade dialética das atividades humanas. Isso nos leva a questionar, de um lado, a dicotomia entre o fazer e o agir, a poiesis e a praxis; de outro lado, a clivagem entre trabalho e nãotrabalho, vida profissional e extra-profissional. Em seguida, apresentaremos sucintamente uma pesquisa-ação relativa ao que significa, do ponto de vista da atividade, o fato de se viver e trabalhar com uma doença crônica, no contemporâneo mundo do trabalho - mas não só nele.
\end{abstract}

Palavras-chave: Atividade. Trabalho. Psicossociologia do trabalho. Doença crônica.

\section{ABSTRACT}

In this article, we try to clarify the meaning given to the words " acting ", " action ", " activity ", " act ", " praxis ", which are close to one another but not synonymous. We will undertake this analysis through the conceptualization of the "activity " in the work psychosociology area with two key questions : what is the purpose of the activity? what is its relationship to work ?Activity remains at the basis of the construction of the person and of the social units. Indeed human activities produce both the self and the world. Moreover we underline here the dialectic unity of human activities. Which leads to

1 Texto traduzido por Nina de Melo Franco.

* Professora émérita de psicossociologia do trabalho, no Centre de Recherche sur le Travail et le Développement (CRTD), do Conservatoire National des Arts et Métiers (CNAM), Paris. Publicou numerosos artigos e livros, entre os quais Placardisés (Seuil, 2002), Cliniques du travail (Eres, 2006), Qualité du travail qualité au travail (Octarés, 2014), Que font les 10 millions de malades? Vivre et travailler avec une maladie chronique, (avec A.M. Waser, Eres, 2016) et Se doper pour travailler (avec G. Lutz et R. Crespin, Eres, 2017). É membro do comitê de redação da Nouvelle Revue de Psychosociologie e do Centre International pour la Recherche, la Formation et l'Intervention en Psychosociologie (CIRFIP).E-mail: dominique.lhuilier@cnam.fr. 
challenge the dichotomy between doing and acting, poiesis and praxis, the splitting between work and "out of work ", professional and extraprofessional life. Then, we will briefly present an action-research dealing with the meaning, from the point of view of the activity, of the fact of living and working with a chronic disease within the contemporary worl of work (but not only).

Keywords : Activity. Work. Work psychosociology. Chronic disease.

\section{RESUMEN}

En este artículo, buscaremos aclarar los sentidos dados a los términos actuar, acción, actividad, acto, praxis, conceptos próximos, pero no sinónimos. Para ello, vamos a proponer una discusión a través de la conceptualización de la actividad, en psicosociología del trabajo, centrándonos en dos cuestiones esenciales: ¿a qué sirve la actividad? ¿Cuáles son las relaciones entre actividad y trabajo? La actividad está en el fundamento de la construcción del sujeto $\mathrm{y}$ de las unidades sociales. En efecto, las actividades humanas son, a la vez, producción de sí y del mundo. Además, subrayamos aquí la unidad dialéctica de las actividades humanas. Esto nos lleva a cuestionar, por un lado, la dicotomía entre el hacer y el actuar, la poiesis y la praxis; de otro lado, la brecha entre trabajo y no trabajo, vida profesional y extra-profesional. A continuación, presentaremos sucintamente una investigación-acción relativa a lo que significa, desde el punto de vista de la actividad, el hecho de vivir y trabajar con una enfermedad crónica, en el contemporáneo mundo del trabajo - pero no sólo en él.

Palabras clave: Actividad. Trabajo. Psicosociología del trabajo. Enfermedad crónica

\section{INTRODUÇÃO}

uscaremos aqui esclarecer os sentidos dados aos termos agir, ação, atividade, ato, práxis. Trata-se de conceitos próximos, mas não sinônimos. Para isso, orientaremos nossa análise através do conceito de atividade, desdobrando essa noção tão polissêmica. Já de início, deixamos clara a necessidade de resistir a três tendências frequentes: a que considera a atividade um fazer operacional, como se isso fosse uma simples evidência; a que considera, ao contrário, que a atividade é profundamente enigmática e incompreensível; por fim, a que reduz sua definição à sua relação com a prescrição: nesse caso, a atividade é o trabalho real, sempre diferente da tarefa.

Temos que ir além e esclarecer a conceitualização do agir e da atividade, na psicossociologia do trabalho, buscando responder à seguinte pergunta: para que 
serve a atividade? Quais são suas relações com o agir? Em seguida, apresentaremos sucintamente uma pesquisa-ação relativa ao que significa, do ponto de vista da atividade, o fato de viver e trabalhar com uma doença crônica no mundo (do trabalho, mas não só nele) contemporâneo.

\section{A ATIVIDADE ESTÁ NA BASE DA CONSTRUÇÃO DO SUJEITO E DAS UNIDADES SOCIAIS}

Esta afirmação procura destacar a centralidade da atividade (e não necessariamente do trabalho, no sentido que lhe é dado com mais frequência, ou seja, o de trabalho produtivo remunerado), tanto nos processos de subjetivação quanto na fabricação do laço social, em suas diversas declinações (interpessoal, coletiva, organizacional, institucional).

\subsection{Os processos de subjetivação visam o sujeito em devir}

O sujeito não é dado; ele se constrói através do processo de subjetivação que é, de fato, um trabalho (cheio de embustes) interminável da busca de si mesmo, de um funcionamento em primeira pessoa, na vida. Esse trabalho busca construir um espaço psíquico diferenciado: longe de serem dadas de início, as capacidades de situar-se, com relação com os outros e com o mundo, de tolerar e reconhecer seus próprios afetos, assim como os dos outros, vão sendo elaboradas ao longo de um percurso, desde o início da vida. O sujeito não existe em si, mas existe como uma perseverança, permeado por divisões e objetivos contraditórios.

Esse trabalho de subjetivação supõe uma dupla base: no corpo, dimensão vital da realidade humana, e no social. Ele implica sentimentos, afetos, componentes sensoriais e perceptivos, bem como a transformação dessa "matéria-prima" da experiência psíquica pela simbolização, necessariamente intersubjetiva: para se ver, se ouvir, se refletir, o sujeito precisa ser olhado, visto, escutado por outro sujeito e, para além dele, pela comunidade dos homens.

Destaquemos aqui que é preciso estar atento aos riscos de uma versão encantada, ou, inversamente, diabólica, do "social": ele não se limita a ser um recurso para o desenvolvimento do sujeito, do mesmo modo que não é sinônimo de alienação. O sujeito é, necessariamente, um sujeito social, no sentido em que não pode se construir fora da relação com o outro. Mas ele pode se dissolver nessa relação, ao sujeitar-se ao outro. Isso ocorre, por exemplo, quando a coesão do grupo impede o acesso à singularização, ou quando o desejo de ser reconhecido pelo outro prevalece sobre o reconhecimento de seu próprio desejo (Enriquez, 2003). 
Mas temos que ir mais longe: o sujeito não está somente engajado na intersubjetividade, "ligado" aos outros pelo imaginário e pelo simbólico, como destaca J. Barus-Michel (1996, p. 265): "A psicologia social clinica pretende analisar um objeto complexo, mas não menos real, aquele dos individuos confrontados com seus semelhantes, na imperiosa necessidade do ato. É preciso apreender essa interação do sujeito, dos outros e da realidade". O elo entre o sujeito e o outro passa pela mediação das relações de transformação da realidade, via essencial de confronto com o real.

O que está em jogo nesse confronto é relembrado por Mendel (1998), fundador da sociopsicanálise e psicossociólogo do trabalho. Para ele, é no ato e apenas no ato que o ser humano conhece a dimensão de uma realidade estranha a seu eu, dimensão esta que resiste a seus desejos, conceitos e projetos. $\mathrm{O}$ ato (ou a atividade) é, portanto, o vetor da prova de realidade e do confronto com o que resiste ao projeto visado (compreender, transformar, dominar, executar...).

Assim, podemos destacar que a construção do sujeito passa pela perda das ilusões de onipotência: querer não é poder. E tal perda solicita o desenvolvimento, tomado aqui no sentido múltiplo de inventividade, de inteligência prática (Dejours, 1993), das artes de fazer (Certeau, 1990), de um poder criador que explora o campo dos possíveis e ultrapassa determinações e repetições.

\section{$2.2 \mathrm{O}$ ato - ou a atividade - está ainda no cerne do desenvolvimento das unidades sociais.}

Em outras palavras, o que constroi sociedade é um conjunto dinâmico de transformação da realidade. Pois qualquer sociedade, qualquer comunidade de homens sempre se solidarizou, ainda que de modo conflituoso, para fazer essa transformação que só pode ser feita através da cooperação. Os conflitos dizem respeito à forma de fazer, decidir, prever; eles levaram e ainda levam a divisões, concorrências e diversidades nos modos de organização (Barus-Michel, 1987).

A conflitualidade social não pode ser reduzida às relações de poder, de dominação, de submissão (onipresente no trabalho, hoje e sempre, se considerarmos o trabalho dos escravos, dos servos, os trabalhos forçados, desde o nascimento do assalariamento e do contrato de subordinação). Ela integra um terceiro termo: essa realidade a transformar e que mediatiza as relaçóes entre sujeitos ou atores.

Os trabalhos de Mendel (1988, 1999), seus conceitos de ato-poder e de movimento de apropriação do ato, esclarecem essa "triangulação" operada pela consideração da realidade, nas relações interpessoais e sociais. Não se trata mais 
aqui somente do poder de uns sobre os outros, mas também do ato-poder. Este conceito tem dois significados. No primeiro caso, há o poder do ato, como poder de transformação do segmento visado da realidade, ou seja, o ato modifica o que havia antes dele; do contrário, ele se choca com um impossível, uma impotência que o torna sem efeito de transformação, ineficaz. No segundo caso, temos o poder sobre o ato do qual dispõe seu autor, ou seja, o ato - ou a atividade - é determinado em suas modalidades e objetivos por seu autor; do contrário, ele não passaria de uma operação executada em conformidade com as diretivas já dadas. Assim, a experiência subjetiva do trabalho depende do grau de poder de que o sujeito dispõe ou que ele constrói, segundo as duas dimensões acima. O que Mendel chama de "movimento de apropriação do ato" resulta de um trabalho individual e coletivo de renormalização.

Canguilhem (1947), ao discutir a obra de Friedmann publicada em 1946, destaca que qualquer homem quer ser sujeito de suas normas. A ilusão capitalista é acreditar que as normas capitalistas são definitivas e universais, sem pensar que a normatividade não pode ser um privilégio. $\mathrm{O}$ que Friedmann chama de 'liberação do potencial do indivíduo' nada mais é do que essa normatividade, que constitui, para o homem, o sentido da sua vida".

Essa concepção da atividade como normatividade junta-se à concepção proposta por François Tosquelles, fundador da psicoterapia institucional e, com outros psiquiatras da psicopatologia do trabalho. Tosquelles (2009) empenhase em distinguir a atividade de uma pura "agitação", de um "movimento heterodeterminado" (p. 25) ou de uma "passividade obediente às prescrições" (p. 45). Ele insiste e nós retomamos essa distinção:

Não devemos confundir o conceito de atividade com a simples realização de movimentos, ou até mesmo de esforços consentidos de aplicação e de perseverança submissa ao desejo do mestre da escola ou do mestre de obras. Atividade quer dizer atividade própria: atividade que parte e enraíza-se no sujeito ativo para crescer, se for o caso, em um contexto social. Pode-se conceber uma escola ou um hospital psiquiátrico em que todos estão ocupados e em que se manifesta uma espécie de agitação, sem que, no entanto, nenhum paciente nem nenhuma criança realizem alguma atividade própria” (p. 46).

Nesse caso, diremos que a atividade é recalcada, contrariada, impedida, quando o sujeito não pode construir uma atividade própria, personalizada e personalizante.

Hoje, no mundo contemporâneo, duas situações contrastadas dominam:

a) a do excesso de trabalho: intensificação do trabalho, pressão temporal, competição 
b) a do subemprego: "bicos", emprego em "tempo parcial" imposto, cada vez mais trabalhadores precarizados ou até mesmo entregues a si próprios, empurrados para fora dos espaços-tempos produtivos.

Há, nos dois casos, uma mesma amputação da atividade própria. Ela pode tomar a forma de uma atividade "empacotada", dissociada do sujeito, formatada e reduzida a um simples "funcionamento". Ou a de uma repressão do movimento e da mobilização psíquica pelo não-trabalho forçado (no caso do "sem trabalho" ou do prisioneiro, por exemplo).

O custo psíquico e o sofrimento ligados aos impedimentos da atividade própria (Lhuilier, 2009) não dizem respeito somente às coerções encontradas no trabalho assalariado. Eles também dizem respeito às situações de desocupação imposta. Consideramos aqui o desemprego externo, relativo ao que chamamos de "buscadores de emprego", e o desemprego interno, que se refere àqueles que são "deixados na geladeira". (Lhuilier, 2002)2.

Em síntese, o que está em jogo na atividade sempre ultrapassa, inclusive no caso do trabalho assalariado, o que tem a ver com a eficácia, a performance e a rentabilidade, tais como definidas pelas racionalidades instrumental ou econômica.

As atividades humanas também são, fundamentalmente e ao mesmo tempo, produção de si e do mundo. Elas sempre incluem uma parte de ação, entendida como práticas sociais de construção e de transformação de um mundo comum. Assim, a atividade tem que estar associada a um trabalho de civilização do real, pelo desenvolvimento dos recursos simbólicos e por um trabalho de humanização.

\section{A UNIDADE DIALÉTICA DAS ATIVIDADES HUMANAS}

Essa problemática pode ser entendida em dois níveis distintos, mas ligados: ela afirma a unidade das atividades, portanto questiona a dicotomia entre o fazer e o agir, a poiésis e a práxis; ela afirma a unidade das atividades, portanto contesta a clivagem entre trabalho e não-trabalho.

\subsection{Não há dicotomia entre fazer/agir:}

Para nós, na psicossociologia do trabalho não há separação entre as duas coisas. Contrariamente a muitas análises que, afinal de contas, são bem clássicas, o trabalho não é a parte maldita da atividade humana (necessariamente sinônimo

\footnotetext{
2 Em francês: mis au placard ou placardisés: expressão cunhada por Lhuilier (2002) para designar aqueles trabalhadores que são deixados de lado, sem se lhes atribuir ou solicitar nenhum tipo de atividade, deixando-os relegados a um espaço sem função. (Nota da tradutora).
} 
de exploração e de alienação), oposta ao campo do político, que seria sua parte nobre, ou à contemplação, depurada das escórias da heterodeterminação. Essa desvalorização do trabalho e das atividades produtivas é acompanhada de uma valorização da práxis e da ação. Ela se inscreve na reta linhagem das conceitualizações de Arendt (1958) e da distinção que ela faz entre trabalho, obra e ação. Como pano de fundo dessa leitura, aparece aqui uma retomada da divisão das atividades humanas, tais como contidas na dicotomia conceitual de Aristóteles: poiésis/práxis ou fazer/agir.

Nas análises que propõem essa leitura, o diagnóstico da modernidade é geralmente o seguinte: hoje, a atrofia da práxis, como ação no sentido próprio, transforma qualquer atividade humana em simples produção, submetida à produção de resultados, a considerações técnicas e estritamente operatórias. A racionalidade instrumental, nessa perspectiva, é muito criticada. O reino da verdadeira práxis, que infelizmente teríamos perdido, é concebido como aquele das atividades de auto-revelação do sujeito e da civilização, no sentido da execução de normas e valores comumente partilhados, indexados à humanização.

Na psicologia do trabalho, contestamos essa distinção paradigmática:

a) a poiésis designa as atividades ligadas às utilidades, aos puros meios. Elas visam o bem viver, em oposição ao viver bem. Essas atividades se declinam e se apreciam em termos de habilidades, de saber-fazer, de expertise do ofício e de eficácia ou eficiência;

b) a práxis, ao contrário, inclui todas as atividades nas quais se exprime nossa capacidade, propriamente humana, de estabelecer finalidades. São atividades sobre as quais se supõe que fazemos uma escolha de objetivos, responsabilizando-nos por elas. A práxis é a esfera na qual se expressam e se realizam nossas identidades pessoais e coletivas, nas quais se afirma o sentido que a vida tem para nós.

No entanto, essas distinções não podem levar a classes de atividades. Com efeito, grande parte de nosso "fazer" é também nosso "agir", e quase tudo que em nós é "agir" também é, ao mesmo tempo, "fazer". Uma práxis que não pode ser poiésis acaba não sendo, de modo algum, uma ação. Não há ação sem organização e realização, sem consideração técnica, assim como não há atividades de produção sem perspectiva de ação, sem debate de valores. A esfera do político não pode ser concebida somente como a da conversação, das controvérsias. Ela também é uma esfera de decisões e de realizações.

A própria produção é sempre a unidade de um duplo processo: a atividade instrumental de trabalho, a poiésis, e a manutenção ou a mudança das formas 
sociais de interação entre os homens, a práxis, que determina o objetivo de qualquer processo de produção. Romper com essa abordagem que separa atividade e ação permite-nos considerar que as atividades têm sempre duas faces, a instrumental e a política, ou seja, que as questôes dos fins e dos meios as atravessam.

$\mathrm{Na}$ perspectiva que defendemos, na psicossociologia do trabalho, o fazer e o agir, a poiésis e a práxis, não são classes distintas de atividades humanas, mas dimensões que perpassam cada uma delas. Assim, a atividade de trabalho, a atividade de produção, no sentido em que a entendemos, é sinônimo de práxis.

Por outro lado, e as grandes preocupações em matéria de saúde no trabalho são testemunhas disso, no conjunto das situações em que a atividade de produção é desarticulada da práxis, em que é reduzida a gestos e condutas programadas, esvaziadas, o sujeito vai se enfraquecendo e sua vida psíquica fica anestesiada.

\subsection{Desconstruir a clivagem trabalho/não-trabalho}

A representação dominante do trabalho hoje o assimila ao trabalho assalariado, como se ele tivesse aparecido à mesma época do nascimento do salário. E mesmo que as ciências do trabalho digam que aí se trata de uma visão centrada na história, as pesquisas e intervenções realizadas dizem respeito, em sua grande maioria, a casos ou situações de trabalho assalariado.

Inversamente, e esta é a nossa posição, reconhecer a diferenciação entre emprego e trabalho implica reconhecer as atividades que não são de lazer, mas fazem as mesmas funçôes do trabalho, no sentido habitual do termo: funções utilitária, social e identitária. Não há descontinuidade entre os diferentes tipos de atividades e as que são economicamente sancionadas. E a questão do trabalho, portanto, não acaba na porta do mundo do trabalho.

O homem está engajado nos diversos campos da vida, que também são, sempre, campos de atividades. Trata-se, então, de analisar as transações, as cooperações, as coordenações e os conflitos entre os diversos mundos de atividades, buscando identificar os recursos e as restriçôes que esses campos de atividades representam, uns em relação aos outros, as competências mobilizadas e transferidas de um campo ao outro. Essa perspectiva está vinculada à unidade dialética das atividades humanas, perspectiva desenvolvida pela psicossociologia do trabalho (Mendel, 1998; Curie, 2000; Lhuilier, 2010).

Ao privilegiar o conceito de atividade, rearticulamos a vida de trabalho e a vida de não-trabalho (fora do trabalho assalariado) para estudar os processos de interação entre as diversas esferas de atividades. A vida no âmbito do não- 
trabalho inclui atividades domésticas, familiares, associativas, sindicais, políticas, de sociabilidade formal e informal... Cada uma delas pode ficar sob o domínio do trabalho profissional e, reciprocamente, fornecer-lhe restriçōes e recursos específicos. Daí a referência à noção de sistema de atividades, regulado pelo modelo de vida (Curie et al., 1987). O modelo de vida é produto da história do sujeito, ou seja, de suas atividades anteriores, mas ele é também orientado pelos projetos deste mesmo sujeito que tenta coordenar os meios e fins visados.

A unidade dialética das atividades humanas (Lhuilier, 2010) resiste à clivagem entre vida profissional e vida extraprofissional. A vida do sujeito baseia-se em uma unidade econômica fundamental (no sentido de economia pulsional), como um processo de intersignificação, porque o sujeito busca o sentido de sua existência em seus diferentes meios de vida.

Podemos mesmo considerar que a injunção à clivagem, levando, de um lado, à polarização entre o aqui e agora da execução de uma tarefa; de outro lado, a um engajamento e uma disponibilidade total de si na atividade profissional, pode ser sinônimo de amputação de si. E, potencialmente, de alienação, pela captura em um único mundo, o da organização da produção e de seus objetivos próprios. A conflitualidade das expectativas, princípios, valores e finalidades dos diversos mundos nos quais nos engajamos evita a univocidade e, portanto, o adormecimento em uma única visão do mundo. Por outro lado, levar em conta somente a atividade de trabalho (distinta da atividade no trabalho) em nossas análises e intervençôes é ser cúmplice, de alguma forma, dessa captação que reduz o homem no trabalho a uma força produtiva.

Além disso, separar o trabalho das outras atividades humanas reduz o movimento da normatividade: poder opor normas pessoais às normas sociais de um trabalho prescrito supóe beber em outras fontes de registro, além daquela do trabalho. Ou supõe fazer uso da experiência da multipolaridade do sujeito, em seus diversos mundos ou campos de vida.

A atividade encontra seus motivos e seus objetivos no conjunto da história da pessoa, em suas dimensões profissionais e não profissionais. $\mathrm{O}$ reconhecimento desses motivos e objetivos, cujas fontes vão muito além da esfera de produção, passa por uma abertura às histórias e situações singulares, o que só é possível, evidentemente, em determinadas condições metodológicas.

Note-se ainda que, no mundo do trabalho, prevalece hoje centralmente a ideia de que se "a vida privada" pode ser convocada para explicar o que se manifesta no trabalho, é sempre na perspectiva de uma atribuição causal do negativo, sob diferentes formas: as causas dos suicídios, acidentes de trabalho, erros humanos, absenteísmo... teriam que ser estudadas na vida extraprofissional, que interfere no engajamento e no desempenho no trabalho. 
Enfim, destacamos aqui que os possíveis sentidos do trabalho para um sujeito dependem, fundamentalmente, de suas articulaçôes com os tempos da vida e as diferentes socialidades, do micro ao macro de suas declinações. A questão dos valores construídos, transmitidos, hierarquizados, mobilizados para visar e apreciar o que é um "bom trabalho", do ponto de vista de seu autor, liga os diversos mundos e os diferentes tempos da história. É por isso que o que dá, para o sujeito, valor ao ato, à atividade, não pode ser reduzido nem à satisfação das necessidades pessoais nem à conformidade com modelos sociais anteriores a ele, mas à sua ligação com controvérsias axiológicas, relativas a valores associados, que ultrapassam cada um dos segmentos das atividades e que também remetem à construção humana da humanidade.

Nem as regras de ofício (Molinier, 2006) nem o gênero de ofício (Clot, 2008) e nem mesmo as regras e valores do coletivo de trabalho podem limitar a questão do sentido do trabalho e de seu reconhecimento. São referências indispensáveis, certamente, mas são também produções sociais vinculadas à divisão técnica e social do trabalho. E essas divisões constituem segmentações das representações do que há a ser feito, do que é essencial que se faça, do que é o trabalho bem feito, em vista das referências próprias ao lugar ocupado nessas divisões e das atividades associadas a elas.

Ajuntemos ainda que a divisão do trabalho também é uma divisão moral e psicológica (Hughes, 1996). Essa divisão fabrica o campo do "trabalho sujo", que compreende tarefas desagradáveis, condenáveis, repugnantes, vergonhosas, que são eivadas de descrédito. Essa fabricação está baseada em processos de delegação e de invisibilização de atividades desinvestidas e desvalorizadas.

Os sujeitos que se encarregam de lidar com o negativo psicossocial (aquilo que é rejeitado, afastado, e cujo tratamento é delegado a profissionais especializados nesta dupla tarefa: manter em segredo e reciclar o negativo em formas positivas reassimiláveis), com o "trabalho sujo", ficam sempre expostos ao confronto com o que é constituído, pelo próprio processo da projeção-expulsão, como "objeto ruim".

O alcance mortífero do "mau objeto" solicita estratégias defensivas ou até mesmo ideologias defensivas (Dejours, 1980) que podem alimentar regras, normas e valores do ofício, a serviço da defesa individual e coletiva. Os corporativismos defensivos fabricam geralmente culturas de ofício muito distantes do trabalho de cultura, entendido como trabalho de civilização, no sentido de Freud (1929). Daí a necessidade, do nosso ponto de vista, de ligar a questão das regras e valores no trabalho, no ofício, à das atividades referentes a outros campos da vida, mas que remetem, todas elas, à construção humana da humanidade. 
É na divisão do trabalho que se enraíza a assimetria social. Assim, o ofício ou o grupo de pares só seriam pertinentes aos debates sobre as finalidades do trabalho se eles puderem debater suas respectivas contribuições através de objetivos e princípios que contribuem para o trabalho de cultura, ou seja, para um trabalho de civilização do real e de humanização.

A construção do sentido do trabalho implica, pois, não só aquele que o realiza com seus pares e os outros profissionais que operam na mesma "produção", mas também o sistema social no qual o trabalho em questão está inserido, e, por fim, a sociedade, através da repartição das grandes funções que contribuem para a sua manutenção.

\section{VIVER E TRABALHAR COM UMA DOENÇA CRÔNICA}

Os avanços da medicina e o envelhecimento da população ativa contribuem para o aumento significativo do número de trabalhadores que vivem com alguma doença crônica, seja ela causada pelo trabalho (LER/DORT, sequelas de acidentes de trabalho, stress pós-traumático, cânceres profissionais...) ou não (diabetes, esclerose múltipla, insuficiência renal, cânceres, hipertensão, poliartrite...). A experiência da vida com uma patologia revela a centralidade da atividade, na resistência à dominação da doença. Ela nos mostra também a necessidade de questionar a clivagem entre vida profissional e vida extraprofissional.

Exploremos aqui os processos de interação entre as diversas esferas de atividades e as regulações internas a cada uma delas e entre elas, tal como podem ser revelados por uma experiência da vida com a doença. Revelados pelo fato de aparecerem, nesse contexto, com mais evidência, pois habitualmente eles permanecem pouco conscientes. Vale lembrar: os "doentes" não têm natureza diferente dos "saudáveis", e a flutuação das capacidades produtivas, assim como a vulnerabilidade vital, são traços ontológicos e não específicos de "populações" singulares.

As regulações internas e externas de cada esfera têm um objetivo adaptativo, pelo fato de que permitem prevenir a ameaça de precarização sanitária e social (degradação do estado de saúde, perda da "empregabilidade"). Mas elas também têm um objetivo de desenvolvimento, na medida em que buscam aumentar o poder de ação do sujeito sobre si mesmo e sobre seu meio ambiente.

Aqui, vamos nos ater a três conjuntos de atividades de transformação de si e do meio:

a) o trabalho de saúde: ele diz respeito, é claro, à coatividade com os profissionais de saúde Strauss, (1992), mas engloba, mais amplamente, as atividades de cuidado (no duplo sentido do care e da cura) de si, as 
autoprescrições que regulam o estilo e a higiene de vida, a reorganização do trabalho requerida pela prescrição médica para ajustá-lo, ao mesmo tempo, às exigências e às restrições das outras esferas de atividades, bem como aos desejos e aspiraçóes do sujeito;

b) as atividades profissionais: o meio profissional também é o âmbito no qual se desenvolve esse trabalho de saúde. Ele orienta, transforma as atividades profissionais e as maneiras de executá-las: organiza os ritmos e horários de trabalho (formais e informais), busca evitar as tarefas mais difíceis fisicamente, cognitivamente e afetivamente, estabelece estratégias de compensação das alteraçōes funcionais, da flutuação de recursos produtivos, reavalia as urgências e prioridades, reduz a exposição a riscos para si e para o outro;

c) as atividades familiares, domésticas: pelas quais o trabalho de saúde também busca se construir e se desenvolver, através da atividade. Aí se rearranjam as concessões, as arbitragens entre o que o "isso" demanda, tanto no espaço familiar quanto no espaço de uma saúde fragilizada. Sem dúvida, essa é a esfera mais singular de todas, na dimensão do trabalho.

\section{OS DILEMAS DA VIDA COM UMA DOENÇA CRÔNICA}

A experiência da doença, mas também dos efeitos colaterais dos tratamentos, revela uma conflitualidade interna feita de exigências contraditórias. As tensões identificadas dizem respeito, ao mesmo tempo, às exigências opostas entre os diferentes campos de atividade e aos objetivos contraditórios em cada uma delas.

Assim, as tensões entre atividades profissionais e atividades de saúde manifestam-se fortemente: no início de um tratamento difícil (ex: quimioterapia), no retorno ao trabalho, depois da licença médica e, globalmente, ao longo da vida profissional que passa a ser atravessada por essa questão essencial: como dar conta do trabalho e do cuidado de si? Como arbitrar entre a necessidade de se cuidar e a necessidade de preservar a situação de trabalho? Como tornar compatíveis as exigências da vida profissional com aquelas relativas ao trabalho de saúde, realizado nas diversas esferas de vida?

Por ocasião de uma pesquisa-ação realizada nessa área (Lhuilier \& Waser, 2016), criamos grupos de pessoas doentes, chamados de "clubes de doença crônica e atividades", ou seja, espaços coletivos para os sujeitos partilharem com os pares os questionamentos e as incertezas que os acompanham, além de elaborar em conjunto estratégias de ação, objetivando a superação dos obstáculos encontrados. 
Nessas reuniōes, podem ser expressos, ao mesmo tempo, o desejo de retomar o próprio trabalho, de retomar contatos, de ficar livre da doença, mas também o medo de retomar o trabalho e, com isso, perder o que se adquiriu na experiência da doença e da vulnerabilidade, bem como dos prazeres de um outro modo de vida; fala-se também muitas vezes do medo de postergar a retomada do trabalho e de se instalar na doença, fazendo dela um "refúgio" que isola e aprisiona.

O desejo de voltar ao posto de trabalho e aos estímulos da vida profissional é tão expresso quanto o temor de ser menos eficaz, de ter um desempenho pior, de se ver na obrigação de pedir ajuda aos colegas e sentir-se culpado, ao lhes impor uma carga de trabalho a mais.

As discussões dizem respeito aos critérios que permitem escolher entre a segurança de se ter um salário e as restrições pouco compatíveis com a preservação das margens de manobra necessárias aos arranjos informais para proteger a saúde. Aparece também a insegurança do trabalho independente que, por outro lado, dá acesso a certa liberdade, na organização do próprio trabalho.

Será que é bom solicitar rearranjos no posto e nos horários de trabalho, a fim de se proteger, mas correndo o risco de receber tarefas pouco interessantes, ou até mesmo de ir parar na "geladeira"? Como saber o que se pode fazer, o que é bom evitar, as maneiras alternativas de trabalho mais eficientes, eficazes e econômicas, em termos de energia e de esforço?

A construção das margens de manobra e de acordos supõe que se possa contar com uma certa previsibilidade: previsibilidade da agenda de trabalho, da programação dos atendimentos (consultas, exames médicos...). Por outro lado, a precariedade dessas duas temporalidades complica a adequação de sua organização temporal.

Além desses dilemas, existem ainda as tensões entre as atividades domésticas e as atividades de saúde. Elas são expressas principalmente pelas mulheres que têm filhos, e mais ainda quando os criam sozinhas. Como assegurar a manutenção das atividades junto aos filhos (desde a preparação das refeiçõos até manter com eles uma relação de qualidade) quando se conjugam exaustão e angústia? A degradação do estado de saúde das mulheres, mas também dos homens, pode desestabilizar a repartição dos papéis na esfera doméstica e familiar: quando a pessoa que cuidava do conjunto de atividades domésticas passa a faltar, as tensões podem até levar à ruptura. E quando a pessoa responsável pela renda da família fica relegada ao espaço doméstico, por ocasião das licenças médicas, ela parece não estar mais em "seu lugar". 


\section{AS CONTRADIÇÕES ENTRE AS DIFERENTES ESFERAS DE ATIVIDADE PODEM MASCARAR OUTRAS TENSÓES INTERNAS A CADA UMA DELAS}

No próprio seio da esfera profissional, muitos sujeitos evocam essa dupla face de seu trabalho: ele ameaça uma saúde já fragilizada e, ao mesmo tempo, é um instrumento de luta contra a doença. Em outras palavras, o trabalho "adoece" e "cura", ao mesmo tempo.

Assim, manter-se no trabalho gera grandes dificuldades, mas abster-se dele (licença médica) é sinônimo de perder as referências que ajudam a enfrentar o sofrimento da doença e dos tratamentos. Essa tensão fica mais clara, logicamente, para quem extrai da vida profissional satisfações benéficas para sua saúde somatopsíquica.

Os questionamentos são duplos: dizem respeito tanto às transformaçôes do trabalho assalariado (ritmos de trabalho, pressão por produção, competição no mercado, mas também social... todo um conjunto de condiçôes de trabalho percebidas como "fontes de stress") quanto às maneiras de se entregar ao trabalho. É bem a questão do uso de si que aqui está sendo colocada: uso de si pelos outros e uso de si por si mesmo (Schwartz, 2000).

A manutenção das atividades nos diversos campos da vida é um sinal e um meio de resistência à doença. Mas também constitui um risco de desgaste, de exaustão de recursos físicos, alterados pela doença e/ou pelo tratamento.

A atividade é, ao mesmo tempo, um risco e um fator "terapêutico". Com efeito, a passividade pode parecer mais protetora, mas também aparece como uma forma mortífera da economia de si, como sinal de que a doença venceu. Consumir a vida com moderação para se preservar equivaleria à suspensão do próprio desenvolvimento, suspensão dos modos de ultrapassar os obstáculos que a saúde fragilizada sempre encontra, na vida cotidiana. Por isso é que há o engajamento na atividade. Mas no mundo do trabalho, os riscos de desgaste prematuro aumentam.

O conflito entre o cuidado de si (cuidar da saúde) e o cuidado com um trabalho bem feito (fazer um trabalho de qualidade) é uma característica maior dos efeitos das organizações de trabalho contemporâneas. Ele é particularmente destrutivo para quem vive com uma doença crônica, mas diz respeito também a todos os trabalhadores, nos dias atuais. Assim, o esforço pessoal impóe-se muitas vezes como variável de ajuste de uma organização de trabalho saturada de restrições: deve-se então "fazer com o que se tem", inclusive quando faltam recursos de saúde, para preservar o que vale a pena ou aquilo que nos faz bem, no trabalho, levando-se em conta os colegas, os destinatários da atividade e as 
regras do ofício. Então, literalmente, cada qual "se entrega"... até à exaustão dos próprios recursos e a um progressivo ou brutal afastamento, fruto de um acidente de trabalho, de uma recaída na doença, de incapacitação, de invalidez, de aposentadoria antecipada... Para poder continuar a "se entregar" ao trabalho, para preservar o engajamento subjetivo indispensável à saúde no trabalho, cada qual expõe sua saúde, sob o risco de aumentar o próprio desgaste no trabalho.

\section{CONCLUSÃO}

$\mathrm{Na}$ perspectiva aqui apresentada, pretendemos mostrar, baseando-nos numa pesquisa-ação, que a atividade é maior do que o trabalho: a via que consiste em abordar o trabalho pela atividade, pelo ato, pelo trabalhar, dispensa, a priori, a necessidade de limitar o campo de investigação e de ação ao quadro convencional do exercício profissional.

As ciências do trabalho, de maneira geral, ganhariam bastante, ao abrir-se a outras perspectivas que integram a unidade e a centralidade da atividade humana. Da mesma forma, estudar o trabalho "através da atividade" transformaria a maneira de pensá-lo, levando-nos a reconhecer que as coisas em jogo no trabalho são mais amplas que a estrita operacionalidade ou rentabilidade, e não se limitam à racionalidade instrumental e econômica.

O trabalho de elaboração e de simbolização, proposto na intervenção ou na pesquisa-ação em psicossociologia do trabalho, permite reforçar o poder de agir sobre as situações problemáticas, assim como desenvolver as "potencialidades sufocadas do ato", a fim de que o sujeito possa, ao mesmo tempo, inventar sua relação singular com a realidade e construir com os outros um trabalho mais humano. 


\section{REFERÊNCIAS}

Arendt, H. (1958-1983). Condition de l'homme moderne. Paris : Calmann-Lévy.

Barus-Michel, J. (1987). Le sujet social: étude de psychologie sociale clinique, Paris, Dunod.

Barus-Michel, J.; Giust-Desprairies, F.; Ridel, L. (1996). Crises, approche psychosociale clinique. Paris: Desclée de Brouwer.

Canguilhem, G. (1947). Préface du livre de G. Friedman, Problèmes humains du machinisme industriel. Paris: Gallimard.

Clot, Y. (2008). Travail et pouvoir d'agir. Paris: PUF.

Curie, J. (2000). Travail, personnalisation et changements sociaux: archives pour les histoires de la psychologie du travail. Toulouse : Octarès.

Curie, J., \& Hajjar, V. (1987). Vie au travail et vie hors travail: la vie en temps partagé. In C. Lévy-Leboyer \& J.-C. Sperandio (Eds.), Traité de psychologie du travail (pp. 37-56), Paris: PUF.

Dejours, C. (1980). Travail, usure mentale. Paris: Bayard, 2000.

Dejours C. (1993). Intelligence pratique et sagesse pratique: deux dimensions méconnues du travail réel. Education permanente, 3(116), p. 47-70.

De Certeau, M. (1990). L'invention du quotidien: arts de faire. Paris: Gallimard.

Enriquez, E. (2003). L'organisation en analyse. Paris: PUF.

Freud S. (1929). Le malaise dans la culture. Paris: PUF.

Hughes, E. (1956-1996). Le regard sociologique : essais choisis. Paris: Editions de l'EHESS.

Lhuilier, D. (2002). Placardisés: des exclus dans l'entreprise. Paris: Le Seuil.

Lhuilier, D. (2009). Travail, management et santé psychique, Connexions, 91, 85-101.

Lhuilier D. (2010) Développement de la clinique du travail. In Y. Clot \& D. Lhuilier. (Dirs.), Agir en clinique du travail. (pp. 205-224). Toulouse: Érès. 
Lhuilier, D., Waser, A. M. (2016). Que font les 10 millions de malades? Vivre et travailler avec une maladie chronique. Toulouse, Érès.

Mendel, G. (1998). L'Acte est une aventure: du sujet métaphysique au sujet de l'actepouvoir. Paris: Éditions La Découverte.

Mendel, G. (1999). Le vouloir de création. Paris: L'Aube.

Molinier, P. (2006). Les enjeux psychiques du travail. Paris: Payot.

Schwartz, Y. (2000). Le Paradigme ergologique ou un métier de philosophie. Toulouse: Octarès.

Strauss, A. L. (1992). La trame de la négociation: sociologie qualitative et interactionniste. Paris: L'Harmattan.

Tosquelles, F. (2009). Le travail à l'hôpital. Toulouse: Eres. 